Egyptian

Orthodontic Journal

\title{
MODIFIED MAXILLARY SPLINT WITH HEADGEAR IN GROWING CLASS II DIVISION 1 CASES
}

\author{
Ahmed A. K. El- Bialy ${ }^{1}$, Mona Abd El-Aziz Montasser ${ }^{2}$ \\ Shadi Kamel Hawwara ${ }^{3}$
}

\section{ABSTRACT:}

The purpose of this study was to evaluate the dentoskeletal effects of Modified Maxillary Splint with Headgear in growing Class II division 1 cases. Sixteen female patients were selected for this study. The mean age of the patients was 10 years, 1 month. All patients were treated by Modified Maxillary Splint with Headgear for an average of 11 months. The cephalometric radiographs and the study models were analyzed and the collected data were subjected to statistical analysis. Statistical paired $\mathcal{T}$ test was done to determine the significant difference between the pretreatment and posttreatment measurements. The Modified Maxillary Splint with Headgear had skeletal and dental effects. The forward maxillary growth was restrained however, the mandibular growth was stimulated. The maxillomandibular relationship was improved. In addition, while the lower incisors showed a noticeable anterior movement and proclination. The overjet was significantly improved. Conclusion: The Modified Maxillary Splint with Headgear was effective in treatment of growing Class II division 1 patients. The appliance produced skeletal and dental effects.

1- Professor and Headof Orthodontics Department, Faculty of Dentistry, Mansoura University

2- Lecturer of Orthodontics, Faculty of Dentistry, Mansoura University.

3- (D.D.S-2006), Damascus University, Syria. 
Egyptian

Orthodontic Journal

\section{INTRODUCTION}

Class II malocclusion is one of the most common orthodontic problems. ${ }^{1}$ Class II malocclusion represents about $21 \%$ of Egyptians especially Class II division $1 .^{2}$ The main etiology of Class II malocclusions is mandibular retrognathia. ${ }^{3}$ About two thirds of typical Class II malocclusions are in fact mostly due to manibular retrusion. A minority of Class II individuals have maxillary protrusion. Many approaches are available for the treatment of developing Class II malocclusions. Early Class II treatment is typically accomplished by using either headgear or functional appliances. ${ }^{4}$ Removable Headgear Splints (RHS), which distribute the headgear force over many teeth, have hygienic and biomechanical advantages. They facilitate cleaning by eliminating bands and prevent spaces, which typically occur when headgear forces are applied to the molars only. (RHS) were shown to restrain maxillary growth, distally tip and displace the maxillary teeth, and restrain the eruption of the posterior maxillary teeth. ${ }^{5}$

\section{MATERIALS AND METHODS}

Subjects: The sample of this study started with eighteen female patients and ended with sixteen patients. The mean age of the patients was ten years one months The patients were selected according to the following criteria:

1) Angle Class II Division 1.

2) Age ranged from 8-11 years.

3) Overjet $>5$

4) High FMA angle.

5) ANB $>4 \mathrm{~mm}$.

\section{Records:}

For all patients the following diagnostic records were made:

I. Photographs (intraoral \&extraoral).

II. Upper and lower casts.

III. Radiographs (Lateral Cephalometric, Panoramic and Hand Wrist radiographs). 
All records were made before and after overjet reduction except the hand wrist and panoramic x-ray films which were taken only before treatment. The patients were treated by Modified Maxillary Splint With Headgear for average 11 months.

\section{Lateral Cephalometric X-ray analysis:}

The pretreatment and posttreatmentcephalometricx-ray films were traced on acetate paper. Then the cephalometric points (landmarks), lines and planes were determined.

\section{Cephalometric points:}

- A Point (Subspinale): The deepest point on the curve of the maxilla between the anterior nasal spine and the dental alveolus.

- B point (Supramentale) : The deepest point on the anterior curve of the mandibular symphysis.

- $\mathrm{N}$ point (Nasion) : A point at the anterior limit of the nasofrontal suture.

- S (Sella) : The center of Sella turcica.

- Me (Menton) : The most caudal point in the outline of the symphysis; it is regarded as the lowest point of the mandible and corresponds to the anthropological gnathion.

- Gn (Gnathion) : The most anteroinferior point on the lateral shadow of the chin.

- Go (Gonion) : The intersection of the lines tangent to the posterior margin of the ascending ramus and the mandibular base.

- ANS (Anterior nasal spine): The tip of the anterior nasal spine, in the median plane.

- PNS point (posterior nasal spine): This is the constructed radiographical point, the intersection of a continuation of the anterior wall of the pterygopalatine fossa and the floor of the nose. It marks the dorsal limit of the maxilla.

- U1: The tip of the upper incisor.

- L1: The tip of the lower incisor. 
- L6M (molar inferius): The mesial contact of the mandibular permanent first molar determined by tangent perpendicular to OL; where double projection gives rise to two points, the midpoint was used.

- U6M (molar superius): The mesial contact of the maxillary permanent first molar determined by tangent perpendicular to OL; where double projection gives rise to two points, the midpoint was used.

\section{Measuring Procedures:}

Cephalometric lines and planes:

- MP (mandibular plane): It extended from Me to Go.

- PP (palatal plane): It extended from ANS to PNS.

- N-Me: Anterior facial height.

- S-Go: Posterior facial height.

- SN (sella-nasion line): The line through $\mathrm{N}$ and $\mathrm{S}$. The line was used for orientation of all head films.

- OL (occlusal plane): A line through is incisonsuperius) and the distobuccal cusp of the maxillary permanent first molar. The line from the initial head film was used as reference line for measurements on all head films.

\section{Linear measurements:}

- U6M / NSP: Distance from distal crown surface of upper first molar to nasion-sella perpendicular line.

- L6M / NSP: Distance from distal crown surface of lower first molar to nasion-sella perpendicular line.

- NSP/U1: Distance from upper incisor tip to nasion-sella perpendicular line.

- NSP/L1: Distance from lower incisor tip to nasion-sella perpendicular line.

- N/ME: Distance from Nasion to Menton.

- S/GO: Distance from Sella to Gonion. 


\section{Angular measurements:}

- SNA: Anteroposterior position of the maxilla relative to the anterior cranial base.

- SNB: Anteroposterior position of the mandible relative to the anterior cranial base.

- ANB: Difference between SNA and SNB.

- MP-SN: Angle between SN and mandibular plane. It gives the inclination of the mandible to the anterior cranial base.

- PP-SN: Angle between SN and palatal plane.

- U1-SN: The posterior angle formed by extending the long axis of the upper incisor to intersect the $\mathrm{SN}$ line.

- L1-MP: The posterior angle between the long axis of the lower central incisor and mandibular plane.

- U1-L1 (inter-incisal angle): The angle between long axis of the maxillary and mandibular incisors.

- Y-axis: Sella-nasion to gnathion angle.

\section{Bite registration for appliance:}

The initial wax bite was taken with the mandible protracted approximately $5 \mathrm{~mm}$ and opened vertically by about $4 \mathrm{~mm}$. To standardize the appliance activation vertically, the construction bite was taken with an Exactobite stick. ${ }^{6}$

\section{Appliance design:}

Modified Maxillary Splint with Headgear was constructed so that labial surfaces of the anterior teeth were covered by the acrylic. The lower incisors were grasped labially in the acrylic in order to avoid their protrusion. On the lingual side, about $3.5 \mathrm{~mm}$ of acrylic support was provided for the incisor crowns. The upper incisors were grasped in acrylic. The position of the mandible was achieved through the long lingual wings of the lower base. The headgear tubes were inserted in the 
acrylic buccal to permanent first molars area. They also were checked from the occlusal point of view for parallelism to be able to insert the inner bow without any problems. The interocclusal area was high enough to allow good retention of the headgear tubes in the acrylic. The inner arms of the face-bow were in the permanent first molars region. The outer bows of the face-bow were directed approximately through the centre of resistance of the maxilla. The magnitude of the extra-oral force was 450-600 g per side and the construction bite was $4 \mathrm{~mm}$. Adequate relief in the acrylic was provided for the lingual frenum. The upper parts covered the palatal half of the occlusal surfaces of the premolars and molars, and the anterior teeth were enclosed in acrylic up to the cervical margin for torque control. The occlusal surfaces of the upper molars and premolars were ground flat transversely, but the sagittal contour was left untrimmed.

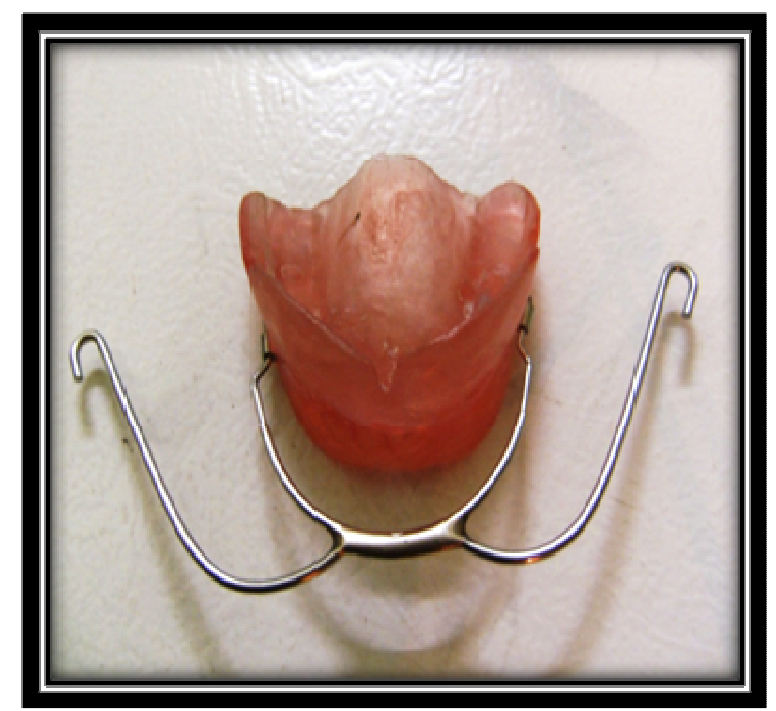

(Figure 1): Modified Maxillary Splint With Headgear. 
Egyptian

Orthodontic Journal

\section{RESULTS}

Table I: The means, standard deviations (SD), and the results of t-test of the pretreatment and posttreatmentcephalometric measurements.

\begin{tabular}{|l|c|c|c|c|}
\hline \multirow{2}{*}{ Measuremens } & Pretreatment & Posttreatment & \multirow{2}{*}{ t } & \multirow{2}{*}{ p-value } \\
\cline { 2 - 3 } & Mean \pm SD & Mean \pm SD & & .000 \\
\hline SNA (degree) & $84.35 \pm 3.08$ & $82.42 \pm 2.62$ & 6.324 & .041 \\
\hline SNB (degree) & $76.15 \pm 2.96$ & $77.97 \pm 2.50$ & -1.927 & .000 \\
\hline SN-MP (degree) & $8.14 \pm 1.27$ & $5.00 \pm 1.03$ & 7.302 & .438 \\
\hline SN-PP(degree) & $39.88 \pm 5.65$ & $37.44 \pm 3.37$ & .816 & .081 \\
\hline Y-axis (degree) & $9.77 \pm .64$ & $10.33 \pm .70$ & -2.00 & .025 \\
\hline N-Me (mm) & $69.55 \pm 4.60$ & $71.33 \pm 4.52$ & -2.74 & .082 \\
\hline S-Go (mm) & $69.55 \pm 5.69$ & $69.77 \pm 5.82$ & .141 & .892 \\
\hline
\end{tabular}

Table II: The means, standard deviations (SD), and the results of t-test of the pretreatment and posttreatment measurements of dental casts.

\begin{tabular}{|l|c|c|c|c|}
\hline \multirow{2}{*}{ Measurements } & Pretreatment & Posttreatment & \multirow{2}{*}{ t } & \multirow{2}{*}{ p-value } \\
\cline { 2 - 3 } & Mean \pm SD & Mean \pm SD & & \\
\hline Overjet $(\mathrm{mm})$ & $7.94 \pm .72$ & $2.37 \pm .51$ & 18.348 & .000 \\
\hline Overbite \% & $.280 \pm .16$ & $.100 \pm .14$ & 1.438 & .027 \\
\hline
\end{tabular}

Significant: $\mathrm{P}<0.05$

\section{DISCUSSION}

Skeletal effects, Maxilla; The results showed that an orthopaedic retraction of the maxillary complex seemed to be consistent. , the SNA angle was significantly decreased. This could be due to the change on the dental maxillary base which occurred when the upper incisors were retroclined. This finding is in agreement with, Van Beek (1982) ${ }^{7}$, O'rton et al. $(1992)^{8}$, Cura and Sarac (1997) and Ruf et al. (2001) ${ }^{10}$. However, opposite results had been in Souza et al $(2004)^{11}$ and Jena et al $(2006)^{12}$. 
Mandible: It has been reported that an increase in mandibular growth is the distinguishing aspect of functional therapy with respect to the other treatment modalities Van Beek (1982), Cura and Sarac (1997), and Almeida-Pedrin et al.,(2007) ${ }^{12}$, while others believe that mandibular length is unaltered by functional appliance therapy Vargervik and Harvotd (1985) In the present study there was an advancement of the mandibular structures resulting from of anterior mandibular displacement. The increase in SNB was statistically significant.

Maxillomandibular relationship: In the current study, maxillomandibular relationship was improved as the ANB angle was significantly decreased.

Vertical dimension: The use of Modified Maxillary Splint with Headgear leads to an increase in vertical development of the mandible. An increase in face height in the first molar region disturbs the balance of vertical development and thereby influences displacement of Pogonion in a backward direction; variations in the vertical dimensions of the maxilla are thus related to the sagittal discrepancy. For this reason, it appears that control of the vertical dimension is imperative for an optimal forward displacement of the correction of a skeletal Class II malocclusion. The results of the present study show non significant changes in vertical development of the maxillomandibular complex: the angular measurements indicated a slight increase in SN - PP and SN-MP angles, the incisors were passively prevented from erupting by double capping as the molars erupted, which resulted in a statistically significant correction of the overbite.

Dental effects: In the present study, correction of upper incisor prominence appeared significant. The overjet correction was due to a combined maxillary and mandibular orthopaedic effect, in addition to lingual movement of the upper dentition, in spite of the teeth being capped in the acrylic. Modified Maxillary Splint With Headgear therapy retroclined the maxillary incisors significantly and significantly reduced the overjet during the observation period. The mandibular incisors proclination significantly increased. Other studies have reported that the mandibular incisors procline or advance significantly during functional appliance treatment in spite of capping. 
Egyptian

Orthodontic Journal

\section{CONCLUSION}

From the present study the followings could be concluded:

1. The Modified Maxillary Splint with Headgear was effective in management of Class II division 1 via skeletal and dental effects.

2. The appliance correction was mainly achieved by a skeletal mandibular reaction, and restraint of forward maxillary growth

3. The dental influences of the appliance include; a retroclination of the upper incisors and proclination of the lower incisors.

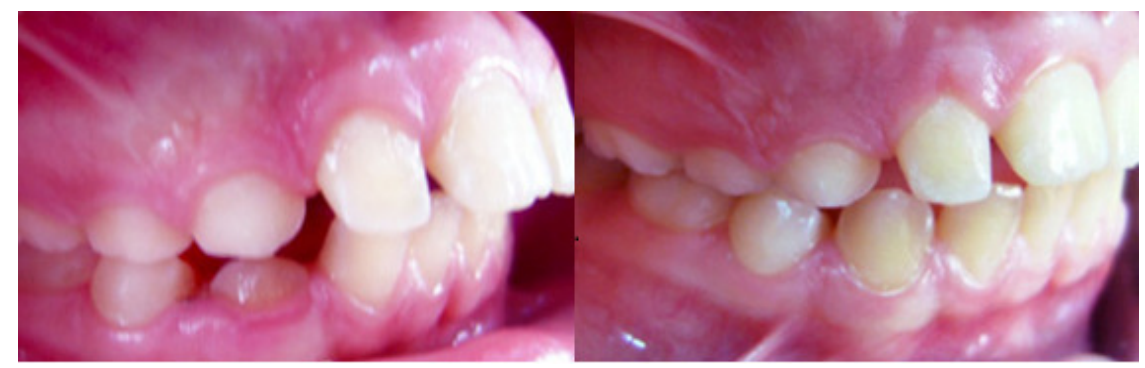

(Figure 2): pre and post treatment photographs of case.

\section{REFERENCES}

1. Proffit WR, Fields Jr HW, Moray LJ: Prevalence of malocclusion and orthodontic treatment need in the United States:. Int J Adult Orthod OrthognathSurg 1998;13:97-106.

2. Fouda M.A.: Disturbance of the accepted occlusion by extraction. Al Azhar D.J 1987;2 (5): 453-67.

3. McNamara Jr JA. Components of class II malocclusion in children 8-10 years of age. Angle Orthod 1981;51:177-202.

4. Tulloch JF, Phillips C, Proffit WR. Benefit of early Class II treatment: progress report of a two-phase randomized clinical trial. Am J Orthod Dentofacial Orthop 1998;113:62-72. 
5. Seckin O, Surucu R. Treatment of Class II, division 1, cases with a maxillary traction splint. Quintessence Int 1990;21:209-15.

6. Eithar Sharif Bashir: Effect of the Jumper Twin Block appliance in Class II division 1 cases. Faculty of Dentistry, Mansoura University, Master degree, 2010.

7. Van Beek H: Overjet correction by a combined headgear and activator. European Journal of Orthodontics 4 (1982) 279-290.

8. Orton HS, Slattery DA, Orton S: The treatment of severe 'gummy' Class II division 1 malocclusion using the maxillary intrusion splint. European Journal of Orthodontics 14 (1992) 216-223.

9. Cura N, Saraç M: The effect of treatment with the Bass appliance on skeletal Class II malocclusions: a cephalometric investigation. European Journal of Orthodontics 19 (1997) 691-702.

10. Ruf S, Bendeus M, Pancherz H, Hägg U: Dentoskeletal Effects and "Effective" Temporomandibular Joint, Maxilla and Chin Changes in Good and Bad Responders to van Beek Activator Treatment. Angle Orthod. 2007;77(1):64-72.

11. Souza E, Janson G, Freitas M, Henriques $\mathbf{F}$ and Cavalcanti C: Occlusal Changes of Class II Malocclusion Treatment between Fränkel and the Eruption Guidance Appliances. Angle Orthod 2004;74:521-525.

12. Almeida-Pedrin RR, Almeida MR, Almeida RR, Pinzan A, Ferreira FP: Treatment effects of headgear biteplane and bionator appliances. Am J Orthod Dentofacial Orthop 2007;132:191-8. 